\title{
Sustainable Construction Using Autoclaved Aerated Concrete (Aircrete) Blocks
}

\author{
Ash Ahmed* and John Kamau \\ Civil Engineering Group, UK \\ *Corresponding author: Ash Ahmed, Civil Engineering Group, UK
}

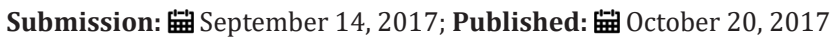

\begin{abstract}
Low Density Aircrete (Density $\leq 450 \mathrm{~kg} / \mathrm{m}^{3}$, compressive strength $\leq 3 \mathrm{~N} / \mathrm{mm}^{2}$ ) has been used extensively for the construction of dwellings in many parts of Europe. In the UK, however, lack of availability has restricted the use of Low Density Aircrete. Developments in Eurocode 6 require adjustment to the UK design procedures, allowing greater utilization of Low Density High Performance Aircrete. The material has considerable advantages, which include its economical, mechanical and physical properties. It is usually manufactured using pulverized fuel ash, which is an industrial by-product. The potential for using Low Density Aircrete for the UK and indeed global construction industry is therefore highly promising with substantial economic and environmental benefits. Furthermore, calculations show the thermal insulating (shielding for hot climates) properties of this material
\end{abstract}

Keywords: Low density aircrete; Sustainable masonry

\section{Introduction}

Aircrete was developed in Sweden in 1924 and first used in the late 1950's [1] as an alternative to building with timber. Currently over 30 million $\mathrm{m}^{3}$ of the material is produced annually. In the United Kingdom it is used extensively by major house builders with block sales of approximately 2.9 million $\mathrm{m}^{3}$ per annum. It is so extensively used that aircrete (mainly medium and high density) now accounts for a third of all concrete blocks in the UK.

Aircrete is also known commercially as AAC (Autoclaved Aerated Concrete), Celcon, Durox, Thermalite and topblock. Aircrete blocks are suitable as vertical load-bearing elements and provide the thermal insulation expected from typical UK wall construction. Aircrete blocks may also be used as non load bearing outer leaves of masonry walls, external walls and walls below ground level, where adequate care is essential to ensure their durability and protection from effects of the environment [2].

The lightweight porous structure and consequent faster build-speed of Aircrete blocks mean even foundations can be constructed quickly, easily and cost-effectively handle creating an extremely effective moisture barrier with significant thermal insulation properties. Their porous cellular structure (porosity) and durability [2,3] make them a recognized alternative in most below ground situations. Aircrete is also now more popular than timber or solid concrete floors in new housing at ground level, and is increasingly the preferred solution for upper floors too. Aircrete's superior thermal performance in most cases eliminates the need for expensive cavity insulation in many cases.
Aircrete is produced by mixing cementitious materials, cement and/or pulverized fuel ash (PFA), lime, sand, water and aluminium oxide powder. The final process involves autoclaving for approximately 10 hours at high temperature and pressure [4-6]. Hence, the material is also known as autoclaved aerated concrete. Aircrete is comprised of $60 \%$ to $85 \%$ of air by volume $(70-85 \%$ for low density Aircrete). The solid material part is a crystalline binder, which is called Tobermorite by mineralogists. Besides the binding phase tobermorite, grains of Quartz and some other minerals are found in minor amounts. The chemical composition of tobermorite comprises of silicium dioxide, calcium oxide and water. It is tobermorite, which provides the high compressive strength of Aircrete in spite of the high proportion of pores in this construction material. This is why low density is sufficiently strong for the construction of dwellings in spite of its considerably high air content.

Thermal conduction is the phenomenon by which heat is transported from high to low- temperature regions of a substance. The high degree of porosity of Aircrete has a dramatic influence on thermal conductivity; increasing pore volume will, under most circumstances reduce thermal conductivity and increase thermal insulation. Heat transfer across pores is ordinarily slow and inefficient [7]. Internal pores normally contain still air, which has extremely low thermal conductivity-approximately $0.02 \mathrm{~W} / \mathrm{m}-\mathrm{k}$. Furthermore, gaseous convection within the pores is also comparatively ineffective. Hence low density Aircrete has outstanding thermal insulation properties [3,8-15] as shown in Table 1. 
Table 1: Physical Properties of Aircrete Blocks.

\begin{tabular}{|c|c|c|c|}
\hline $\begin{array}{c}\text { Aircrete } \\
\text { Density }\end{array}$ & $\begin{array}{c}\text { Compressive } \\
\text { Strength (N/mm2) }\end{array}$ & $\begin{array}{c}\text { Density } \\
\text { (Kg/m3) }\end{array}$ & $\begin{array}{c}\text { Thermal Conductivity } \\
\text { (W/mK) }\end{array}$ \\
\hline Low & $2.0-3.5$ & 450 & $0.09-0.11$ \\
\hline Medium & $4.0-4.5$ & 620 & $0.15-0.17$ \\
\hline High & $7.0-8.5$ & 750 & $0.19-0.20$ \\
\hline
\end{tabular}

The compressive strength of Aircrete is related to its density and increases with increasing density $[1,16]$. Commonly produced compressive strengths are 2.8, 3.5, 4.0, 7.0 and $8.4 \mathrm{~N} / \mathrm{mm}^{2}$ (MPa) as indicated on Table 1 . In the UK compressive strengths $>4 \mathrm{~N} / \mathrm{mm}^{2}$ are commonly used, however, in Europe lower strength Aircrete has been successfully utilized for the construction of dwellings, implying lower compressive strength will be adequate. The compressive strength of Aircrete is nearly independent of specimen size due to its homogeneity [16]. Aircrete achieves its final strength during the autoclaving process without further curing being necessary.

The cellular structure [17-19] of the material ensures a lightweight construction. During installation, most Aircrete blocks can be lifted with one hand providing significant productivity advantages. The higher porosity of low density Aircrete ensures that the material is extremely lightweight (density $\leq 450 \mathrm{~kg} / \mathrm{m}^{3}$ ), thus, it is even easier to handle in comparison to medium and high density Aircrete. As a result transportation costs would be reduced and furthermore, houses would be built much more quickly (Figure1). The combination of the internal structure and the stiffness characteristics of Aircrete enable sound reduction performance for walls and partitions often superior to other types of masonry [3-5].

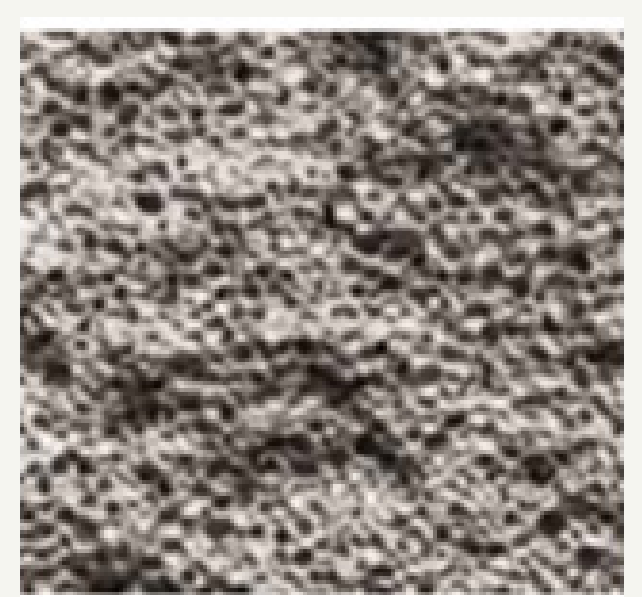

Figure 1: Cellular structure of Aircrete with levels of porosity up to $85 \%$.

Sound absorption is a property relevant to particular applications. When exposed to sound, the aerated internal structure of Aircrete provides good sound absorption properties. Therefore, lower density Aircrete should impart superior sound insulation properties.

Moisture movement through porous building materials is a very complex process $[20,21]$ and for practical predictions simplifying assumptions have to be introduced. There are at least three different origins of water in Aircrete. Immediately after autoclaving Aircrete contains typically about 30\% water by weight of the dry material. This excess water is lost under normal conditions to the surrounding air after a few years [3]. If the relative humidity of the surrounding air increases temporarily, aircrete will take up water again by absorption and capillary condensation. If the surface of a structural element is in contact with liquid water the material absorbs water quickly by capillary suction $[4,20,21]$. Although low density aircrete has a very high proportion of air, the pores are fine and are not interconnected; therefore, the material offers good resistance to moisture penetration. Vapour resistivity of Aircrete is approximately $60 \mathrm{MNs} / \mathrm{gm}$. The resistance to freezing of a construction material is determined by its pore size distribution and, in particular, the percentage, size and shape of capillary pores and the mechanical strength of the inner pore walls [16,22,23]. If the pores of the material become filled with water, which then freezes the ice which has a volume $9 \%$ greater than water will cause pressure on the pore walls. When the tensile strength of the wall material is exceeded, cracking occurs. If the pores are filled with water to a critical degree, and if there is repeated freeze/ thaw cycling, the whole structure may eventually be destroyed. Aircrete possesses good resistance to freezing, which is proved by unrendered buildings, situated in areas where frequent freeze/ thaw cycles occur, remaining undamaged. The reason for the good resistance is that the included spherical pores are almost all closed, meaning the material has comparatively low capillary suction and therefore the moisture content does not normally reach the critical degree. With low density Aircrete, the greater free volume of the material is better equipped for dealing with the pressures caused by freezing of water. Furthermore, as discussed earlier, as the pores are not interconnected, this radically reduces the possibility of water absorption. The high freeze thaw resistance in essence is due to the aerated internal structure of the material. The resistance to frost is superior to that of many stronger denser masonry materials although the degree of resistance is to some extent dependent on strength and density.

\section{Durability and fire resistance}

The resistance of Aircrete to attack from sulfates likely to be found in soils and ground water is high $[2,21,24]$ and related to the strength and density. Aircrete has excellent resistance to sulphate attack up to sulphate concentrations of $600 \mathrm{mg} / \mathrm{l}$ in the water. For higher concentration levels special protective precautions are necessary [2,21]. One method of protection to Aircrete in subsoil is to apply protective coatings usually based on bitumen [16].

Aircrete blocks have excellent fire resistance, it's performance can be summarized as follows:

a. Aircrete blocks do not burn. They are classified as noncombustible, having a Euroclass of A1 (the highest possible) and have a "class 0 (zero) surface spread of flame" as described in the National Building Regulations [10]. The surface spread of flame tests in BS 476: Part 7 defines spread of flame as the "propagation of a flame front over the surface of a product under 
the influence of imposed radiance". Aircrete (of all densities) limit flame propagation.

b. As a result of aircrete's inherent fire resistant properties, the product can be used to contain or prevent the spread of fire within a building, Extensive research has shown aircrete helps maintain the stability and structure of a building in the event of a blaze, whilst, and perhaps more importantly, allowing the occupants vital time to escape.

c. By simply using a $100 \mathrm{~mm}$ aircrete masonry block in the construction, up to 4 hours fire resistance can be achieved on non load-bearing walls, and up to 2 hours on load- bearing walls.

d. Where aircrete is used to construct internal walls, partitions and external walls, the resistance to fire is significantly improved as aircrete blocks can resist temperatures of up to $1200^{\circ} \mathrm{C}$.

e. Even after a fire aircrete walls have been shown to have sufficient strength and robustness to be retained.

f. Aircrete does not emit toxic smoke or gases when subjected to fire.

g. Aircrete manufacturers work closely with fire researchers in order to maximize fire safety standards and aircrete's fire resistant properties have been proved during testing and real case scenarios.

h. Actual case histories have proved aircrete's capability in real fires, not only as a fire- break wall, but also as protective cladding for other forms of construction, for example steel frames.

i. Aircrete is non-combustible and there is no risk of the superstructures smouldering after the fire appears to have been extinguished.

As a result all Aircrete products provide excellent fire protection and satisfy the requirements of Part B of the Building Regulations [4-8] and in so doing ensure:

a. An adequate means of escape.

b. Internal surfaces of the building inhibit the spread of flame.

c. The structure of a building is sufficiently fire resistant to the spread of fire and retains its stability for a reasonable period of time.

d. The external surfaces of the building offer adequate resistance to the spread of fire from one building to another.

The excellence resistance to fire entails aircrete as one of the best construction materials for resisting fire, this is of fundamental importance and its implications cannot be understated, especially in the light of the tragic and horrifying scenes at Grenfell Tower, London (2017) which resulted in many fatalities. The utilization of aircrete would undoubtedly result in the saving of many lives $[25,26]$.

\section{Workability and dimensions}

All Aircrete products have exceptionally good workability and are easy to cut, shape and chase using ordinary woodworking tools. This makes them ideal for closing the cavity at reveals and for cutting around and over joists, or for special shapes such as in fills. Blocks are easily cut using hammer and bolster or wood saw. A straight cut ensures less wastage and reduces the need to make good. Hammer and wood chisels can be used for chasing-out. Woodworking drill bits can be used to accommodate wall plugs before fixing screws. Due to its higher porosity and lower strength, low density Aircrete has good workability properties. This substantially reduces waste. Aircrete blocks are produced in a range of thickness from $60 \mathrm{~mm}$ to $355 \mathrm{~mm}$ with a range of face dimensions. The most common work face dimensions are 440 or $620 \mathrm{~mm}$ long by $215 \mathrm{~mm}$ high. Other work face dimensions are also available ranging from coursing bricks $215 \mathrm{~mm}$ long by $65 \mathrm{~mm}$ high to large format blocks $620 \mathrm{~mm}$ long by $440 \mathrm{~mm}$ high.

\section{Reduction of thermal transmittance (U) using low density aircrete}

It can be demonstrated that the thermal efficiency of Aircrete is inversely proportion to compressive strength [1]:

For $2.8 \mathrm{~N} / \mathrm{mm}^{2}$ (compressive strength) blocks: Thermal Conductivity $=0.11 \mathrm{~W} / \mathrm{mK}$

For $4 \mathrm{~N} / \mathrm{mm}^{2}$ (compressive strength) blocks: Thermal Conductivity $=0.14 \mathrm{~W} / \mathrm{mK}$

For $7.0 \mathrm{~N} / \mathrm{mm}^{2}$ (compressive strength) blocks: Thermal Conductivity $=0.19 \mathrm{~W} / \mathrm{mK}$

The requirements of Part $\mathrm{L}$ of the Building Regulations became more stringent recently in order to reduce $\mathrm{CO}_{2}$ emissions from buildings $[1,2,4,5,8,9]$. There is greater attention to air leakage and cold bridging with the introduction of Robust Details developed with industry. Aircrete blocks continue to provide wall and floor constructions that meet and exceed the regulatory requirements.

Dwellings constructed from the lower strength / density material have a lower thermal transmittance (U-value). The U-value for a dwelling constructed from $7 \mathrm{~N}$ blocks is up to over $50 \%$ higher than one constructed from $2 \mathrm{~N}$ blocks. Also, as the thickness for thin joint mortar is significantly less than that for conventional mortar ( 3 as opposed to $10 \mathrm{~mm}$ ), this results in dwellings constructed from conventional mortar having U-values approximately $10 \%$ greater than those constructed using thin joint mortar [27].

The average U-value of a typical dwelling with a wall construction comprising a cavity wall with a brick outer leaf, a cavity partially filled with $17 \mathrm{~mm}$ of Celotex and a $115 \mathrm{~mm}$ Aircrete (med / high density) inner leaf finished with $13 \mathrm{~mm}$ dense plaster internally is 0.53 [2]. For a dwelling constructed with solid, $300 \mathrm{~mm}$ thick $2 \mathrm{~N}$ Aircrete blocks with thin joint mortar, the U-value is 0.51 . Therefore, the utilization of low density Aircrete eliminates the necessity for cavity wall construction [27]. This would not only save money but also reduce the building time, hence, increasing productivity whilst simultaneously reducing carbon energy consumption. 


\section{Conclusions}

a. The strength of low density autoclaved aerated concrete is sufficient to construct two storey domestic dwellings.

b. Aircrete offers excellent thermal resistance and in many instances solid low density Aircrete walls could abrogate the need for cavity wall insulation.

c. Low density Aircrete offers excellent resistance to frost, sufficient resistance to sulphates and is one of the best construction materials for fire resistance.

d. The low density of Aircrete results in rapid construction speeds.

e. Using PFA to produce Aircrete reduces the need for waste to be disposed of in landfill sites.

f. Aircrete has one of the best fire resistance of any construction material.

\section{Acknowledgement}

The authors would like to acknowledge the funding and support for the Low-Density aircrete project given by the EPSRC and industrial partners, Autoclaved aerated concrete products association (made up by $\mathrm{H}+\mathrm{H}$ Celcon, Marley building materials, Quinn-Group and Tarmac topblock) Building Research Establishment-BRE, Catnic-Corus UK, National House-Building Council-NHBC and Office of The Deputy Prime Minister-ODPM.

\section{References}

1. H+H Celcon Ltd, Celcon House, Ightham, Sevenoaks, Kent, TN 15 9HZ England.

2. Code of best practice for the use of aircrete products.

3. Dubral W, Ytong AG (1992) Advances in autoclaved aerated concrete. In Wittmann (Ed.), Balkema, Rotterdam, Munich, Germany.

4. Mitsuda T, Kiribayashi T (1992) Influence of hydrothermal processing on the properties of autoclaved aerated concrete, Advances in autoclaved aerated concrete. In: Wittmann (Ed.), Balkema, Rotterdam, Munich, Germany.

5. Isu N, Mitsuda T (1992) Influence of quartz particle size on the chemical and mechanical properties of autoclaved lightweight concrete, Advances in autoclaved aerated concrete. In: Wittmann (Ed.), Balkema, Rotterdam, Munich, Germany.

6. Pospisil F (1992) Unit weight reduction of fly ash aerated concrete, Advances in autoclaved aerated concrete. In: Wittmann (Ed.), Balkema, Rotterdam, Munich, Germany.

7. Callister W (2010) Department of metallurgical engineering, The University of utah, Materials science and engineering-An Introduction ( $5^{\text {th }}$ edn.), JohnWiley and Sons. Inc, New Jersey, USA.

8. Lippe K, Ytong AG (1992) R+D Centre, The effect of moisture on the thermal conductivity of AAC, Advances in autoclaved aerated concrete. In: Wittmann (Ed.), Balkema, Rotterdam, Munich, Germany.

9. Daian JF (1992) Laboratoire d'etude des Transferts en Hydrologie et Environment (IMG), Grenoble, France, Experimental determination of AAC moisture transport coefficients under temperature gradients, Advances in Autoclaved Aerated Concrete, Wittmann (ed.) (c) Balkema, Rotterdam.

10. Thermalite (2003) Marley Building Materials Ltd, Station Road, Coleshill, Birmingham B46 1HP. www.thermalite.co.uk
11. Laurent J, Frendo-Rosso C (1992) Laboratoire d'etude des Transferts en Hydrologie et Environment (IMG), Grenoble, France, Application of image analysis to the estimation of AAC thermal conductivity,Advances in Autoclaved AeratedConcrete, Wittmann(Ed.)(C Balkema, Rotterdam. ISBN 9054100869.

12. Millard W (1992) Marley Building Materials Limited, The thermal performance of European autoclaved aerated concrete, Advances in Autoclaved Aerated Concrete, Wittmann (Ed.) (C) Balkema, Rotterdam. ISBN 9054100869.

13. Liu C, Wang J (1992) Suzhou Concrete and Cement Products Research Institute, China, An experimental study on thermal transmission properties of aerated concrete composite panels,Advances inAutoclavedAerated Concrete,Wittmann (Ed.)@ Balkema, Rotterdam. ISBN 9054100869.

14. Schlegel E, Volec J (1992) Bergakademie, Freiberg, Germany, Application of autoclaved aerated concrete for high temperature insulation,Advances inAutoclavedAerated Concrete, Wittmann (Ed.) (C) Balkema, Rotterdam. ISBN 9054100869.

15.Wittman FH (1993) Autoclaved Aerated Concrete: Properties, Testing and Design, RILEM Recommended Practice, RILEM Technical Committees 78-MCAand 51-ALC.

16.Tada S, (1992) Texte, Inc. and Nihon University, Japan. Pore structure and moisture characteristics of porous inorganic binding materials, Advances in Autoclaved Aerated Concrete, Wittmann (Ed.) (c) Balkema, Rotterdam. ISBN 9054100869.

17.Jacobs F, Mayer G (1992) Institute for Building Materials, ETH Zurich, Switzerland, Porosity and Permeability of autoclaved aerated concrete, Advances in Autoclaved Aerated Concrete, Wittmann (Ed.)@ Balkema, Rotterdam. ISBN 9054100869.

18.Schober G, Hebel AG, Emmering (1992) Germany, Effect of size distribution of air ports in AAC on compressive strength, Advances in Autoclaved Aerated Concrete, Wittmann (Ed.) (c) Balkema, Rotterdam. ISBN 9054100869.

19. Hasegawa T (1992) Department of Architecture, Faculty of Engineering, Hokkaido University, Sapporo, Japan, Investigation of moisture contents of autoclaved lightweight concrete walls in cold districts, Advances in Autoclaved Aerated Concrete, Wittmann (Ed.) (C) Balkema, Rotterdam. ISBN 9054100869.

20.Wittman FH (1993) Autoclaved Aerated Concrete: Properties, Testing and Design, RILEM Recommended Practice, RILEM Technical Committees 78-MCA and 51-ALC, (1 ${ }^{\text {st }}$ edn.), New York, London, UK.

21.Senbu O, Kamada E (1992) Mechanism of frost deterioration of AAC, Advances in autoclaved aerated concrete. In: Wittmann (Ed.), Balkema, Rotterdam, Munich, Germany.

22. Hama Y, Kamada E (1992) Frost resistance of increased density autoclaved aerated concrete, Advances in autoclaved aerated concrete. In: Wittmann (Ed.), Balkema, Rotterdam, Munich, Germany.

23.Spicker G, Ytong AG (1992) R+D Centre, Chemical resistance of AAC, Advances in autoclaved aerated concrete. In: Wittmann (Ed.), Balkema, Rotterdam, Munich, Germany.

24.Ahmed A, Fried AN, Limbachiya MC, Roberts JJ (2004) Advantages and implications of high performance low density aircrete product for the UK construction industry, $13^{\text {th }}$ International brick/block masonry conference, Amsterdam, Netherlands, pp. 1-10.

25. Fudge CA (2000) Developments with the thin-joint AAC masonry in the UK, $12^{\text {th }}$ International brick/block masonry conference, Madrid, Espana, Spain, pp. 25-28.

26. Nishiyama M, Izawa S, Nishino K (2000) Experimental study on strength of thin joint, $12^{\text {th }}$ International brick/block masonry conference, Madrid, Espana, Spain, pp. 25-28.

27.Ahmed A, Kamau J (2017) Advantages and implications of low density aircrete products for the construction industry, International Journal of Science, Environment 6(3): 1758-1767. 